\title{
Heteropoly Tungstate Supported on Metal Oxide Catalysts for Liquid Phase Oxidation of Benzyl Alcohol with Hydrogen Peroxide
}

\author{
Han Xiaoxiang, ${ }^{*, a}$ Kuang Yingying, ${ }^{a}$ Xiong Chunhua,${ }^{a}$ Tang Xiujuan, ${ }^{b}$ Chen Qing, ${ }^{a}$ \\ Wang Kuiwu, ${ }^{a}$ Hung Chin-Te, ${ }^{c}$ Liu Li-Lic ${ }^{c}$ and Liu Shang-Bin ${ }^{*}, c$ \\ ${ }^{a}$ Department of Applied Chemistry and ${ }^{b}$ College of Environmental Science and Engineering,
Zhejiang Gongshang University, 310018 Hangzhou, China
}

'Institute of Atom and Molecular Sciences, Academic Sinica, 10617 Taipei, Taiwan

\begin{abstract}
A series of metal oxide supported tungstophosphoric acid catalysts were prepared by impregnation. The physicochemical and acidic properties of these materials were characterized by a variety of different analytical and spectroscopic techniques, namely Fourier transform infrared spectroscopy (FTIR), X-ray diffraction (XRD), Brunauer-Emmett-Teller (BET) method, and nuclear magnetic resonance (NMR), and exploited as heterogeneous catalysts for selective oxidation of benzyl alcohol $(\mathrm{BzOH})$ with hydrogen peroxide $\left(\mathrm{H}_{2} \mathrm{O}_{2}\right)$. Among them, 20 wt.\% $\mathrm{H}_{3} \mathrm{PW}_{12} \mathrm{O}_{40} / \mathrm{CeO}_{2}$ catalyst exhibited the best oxidative activity. Further process optimization by response surface methodology (RSM) based on the Box-Behnken design model resulted in a benzyl alcohol conversion of $95.2 \%$ and a benzaldehyde yield of $94.2 \%$ with $98.9 \%$ selectivity, in good agreement with the experimental results. Kinetic studies based on an irreversible parallel reaction model led to an activation energy $\left(\mathrm{E}_{\mathrm{a}}\right)$ of $44.73 \mathrm{~kJ} \mathrm{~mol}^{-1}$.
\end{abstract}

Keywords: ceria, heteropolyacid, oxidation, reaction engineering, process optimization

\section{Introduction}

Aldehydes and ketones, which are important chemical intermediates, play critical roles in chemical industries and have been extensively used in drugs, additives and spices industries. ${ }^{1-4}$ These carbonyl compounds are normally produced by selective catalytic oxidation, which has been widely used in clean production of chemicals..$^{5-9}$ One of the major concerns for oxidation reaction is product selectivity, a challenge arising from the fact that most products are thermodynamically unstable. Typically, transition-metal salts or complexes, especially precious metals, are commonly used as homogeneous or heterogeneous catalysts for oxidation reactions. ${ }^{10}$ However, excessive consumptions of these metal catalysts are not only cost-ineffective but also created a great number of heavy-metal wastes. Thus, the development of green, cheap, and efficient catalyst systems is a demanding task. In this context, the research and development (R\&D) of eco-friendly catalysts such as polyoxometalates (POMs) catalysts have received considerable attention. Among them, heteropolyacids (HPAs) with Keggin-type structure,

*e-mail: hxx74@126.com; sbliu@ sinica.edu.tw which possess unique features such as low volatility, noncorrosive, non-toxic, strong Brønsted acidic strength, and excellent redox properties, have been extensively studied and utilized as solid acid catalyst for heterogeneous reactions. ${ }^{11-14}$ Nonetheless, owing to their high solubility in polar solvents, HPA-based catalyst systems are drawback by their difficulty in catalyst separation and recycling. As such, modified HPA catalysts, particularly those that may be easily prepared using a feasible support, open up a wide new possibilities to unravel the aforementioned problems. ${ }^{15-18}$ As such, while metal or heteroatom substituted HPAs with an exotic variety of structures and compositions have been widely utilized in heterogeneous and/or homogeneous reactions, ${ }^{19-21}$ it is highly desirable to support them on a porous solid substrate with unique catalytic and porous properties. The high surface area available for the supported HPA catalyst was found to promote diffusion of reactants/products and dispersion of active sites to warren high catalytic activity with improved product quality, reduced production costs as well as a prolonged catalyst life due to improved robustness, recovery, and recyclability. ${ }^{22-26}$

In the present work, we aim at the preparation of ceria $\left(\mathrm{CeO}_{2}\right)$ supported tungstophosphoric acid $\left(\mathrm{H}_{3} \mathrm{PW}_{12} \mathrm{O}_{40}\right.$; 
HPW) catalysts by means of incipient wetness impregnation method. The physicochemical properties of these $\mathrm{HPW} / \mathrm{CeO}_{2}$ composites were characterized by a variety of different techniques, viz. Fourier transform infrared spectroscopy (FTIR), X-ray diffraction (XRD), BrunauerEmmett-Teller (BET) method, and solid-state ${ }^{31} \mathrm{P}$ magic-angle spinning (MAS) nuclear magnetic resonance (NMR). The catalytic performances of these supported catalysts were assessed by oxidation of benzyl alcohol $(\mathrm{BzOH})$ with hydrogen peroxide $\left(\mathrm{H}_{2} \mathrm{O}_{2}\right)$. The corresponding reaction process and product optimization were studied by response surface methodology (RSM) and a kinetic model was also established for the alcohol oxidation reaction under optimized conditions. The satisfying catalytic activity observed for the supported $\mathrm{HPW} / \mathrm{CeO}_{2}$ catalysts may be attributed to the unique redox properties and oxygen storage capacity (OSC) $)^{27-30}$ as well as the desirable strong acidity and capability of activating oxidant during oxidation of alcohol. ${ }^{31,32}$ By comparison, other POMs-based catalysts such as $\mathrm{PMo}_{11} \mathrm{Co}$ showed lower catalytic activity with only ca. $51 \%$ benzaldehyde yield during oxidation of $\mathrm{BzOH}$ with $\mathrm{H}_{2} \mathrm{O}_{2} \cdot{ }^{21}$

\section{Experimental}

Materials and catalyst preparation

Analytical grade ceria $\left(\mathrm{CeO}_{2}\right)$, titania $\left(\mathrm{TiO}_{2}\right)$, zirconia $\left(\mathrm{ZrO}_{2}\right)$, benzyl alcohol $\left(\mathrm{C}_{6} \mathrm{H}_{5} \mathrm{CH}_{2} \mathrm{OH} ; \mathrm{BzOH}\right)$, hydrogen peroxide $\left(\mathrm{H}_{2} \mathrm{O}_{2}, 30 \%\right)$, tungstophosphoric acid $\left(\mathrm{H}_{3} \mathrm{PW}_{12} \mathrm{O}_{40}\right.$; HPW), and other chemicals were purchased commercially and used without further purification unless otherwise specified.

All supported $\mathrm{HPW} / \mathrm{CeO}_{2}$ catalysts were synthesized using an incipient wetness impregnation method with varied HPW to total weight of $\mathrm{HPW}$ and $\mathrm{CeO}_{2}$ ratios. The supported catalyst samples so prepared are hereafter denoted as $\mathrm{xHPW} / \mathrm{CeO}_{2}$, where $\mathrm{x}=15-25 \mathrm{wt} . \%$. For example, the $20 \mathrm{HPW} / \mathrm{CeO}_{2}$ catalyst was prepared by impregnating ca. $4.0 \mathrm{~g}$ of ceria support with a $3 \mathrm{~mL}$ aqueous solution of HPW (115.8 $\left.\mathrm{mmol} \mathrm{L}^{-1}\right)$ for $12 \mathrm{~h}$, followed by first drying overnight at $120^{\circ} \mathrm{C}$, then calcined at $250{ }^{\circ} \mathrm{C}$ in static air for $4 \mathrm{~h}$. Similar procedures were used to prepare other supported catalysts.

\section{Catalyst characterization}

FTIR measurements were performed at room temperature on a Bruker IFS28 spectrometer. Each spectrum was accumulated by 32 scans between the range of $400-4000 \mathrm{~cm}^{-1}$ at a resolution of $1 \mathrm{~cm}^{-1}$. X-ray diffraction (XRD) studies were conducted on a Bruker D8 ADVANCE diffractometer equipped with a Ni-filtered $\mathrm{Cu} \mathrm{K} \alpha$ radiation operated at $40 \mathrm{kV}$ and $20 \mathrm{~mA}$. The room temperature XRD patterns were recorded within a $2 \theta$ angle range of $5-80^{\circ}$ at a scanning rate of $10^{\circ} \mathrm{min}^{-1}$. $\mathrm{N}_{2}$ adsorption/desorption isotherm measurements were performed on a Quantachrome NOVA 1000e physisorption analyzer operating at $-196{ }^{\circ} \mathrm{C}$. The acid properties of various catalyst samples were characterized by means of a ${ }^{31} \mathrm{P}$-TMPO MAS NMR approach, namely solid-state ${ }^{31} \mathrm{P}$ magic-angle spinning (MAS) NMR of adsorbed trimethylphosphine oxide (TMPO) probe molecule. ${ }^{33-37}$ All ${ }^{31} \mathrm{P}$ spectra of adsorbed TMPO on various solid acid catalyst samples were recorded at a Larmor frequency of $202.46 \mathrm{MHz}$ using a single-pulse sequence under the conditions: pulse-width $(\pi / 6), 1.5 \mu \mathrm{s}$; recycle delay, $10.0 \mathrm{~s}$; sample spinning rate, $12 \mathrm{kHz}$. The ${ }^{31} \mathrm{P}$ chemical shifts $\left(\delta^{31} \mathrm{P}\right)$ were referred to that of $85 \% \mathrm{H}_{3} \mathrm{PO}_{4}$ aqueous solution. Detailed sample preparing procedures involved for acidity characterization using the ${ }^{31} \mathrm{P}-\mathrm{TMPO}$ MAS NMR approach can be found elsewhere. ${ }^{33,34,39}$

\section{Catalytic reaction}

The catalytic activities of various catalysts were assessed by oxidation of benzyl alcohol $(\mathrm{BzOH})$ with hydrogen peroxide $\left(\mathrm{H}_{2} \mathrm{O}_{2}\right)$. The reactions were conducted in a reactor consisting of a three-necked flask $(100 \mathrm{~mL})$ and a condenser. Typically, equal molar amount (0.05 M) of $\mathrm{BzOH}$ and $\mathrm{H}_{2} \mathrm{O}_{2}$ were introduced to the catalyst in the reactor, the mixture was stirred at a desired reaction temperature for a given period of time. Upon completion of reaction, the reaction mixture was separated by extraction with ethyl acetate. A gas chromatography (GC; Agilent 7890B) analyzer equipped with a flame ionization detector (FID) and an HP-5 capillary column was used to analyze the compositions of reaction mixture in conjunction with authentic samples.

\section{Experimental design and mathematical model}

On the basis of single factor experiments, response surface methodology (RSM) study assisted by a DesignExpert 6.0.5 software (Stat-Ease, USA) was employed to optimize the reaction parameters of $\mathrm{BzOH}$ oxidation reaction over the $20 \mathrm{HPW} / \mathrm{CeO}_{2}$ catalyst, which was found to show best catalytic performance (vide infra). A threelevel, four-variable Box-Behnken design (BBD) model was adopted to investigate the effects of four independent process variables, namely amount of catalyst $\left(x_{1}\right)$, $\mathrm{BzOH} / \mathrm{H}_{2} \mathrm{O}_{2}$ molar ratio $\left(x_{2}\right)$, reaction time $\left(x_{3}\right)$, and 
amount of water $\left(x_{4}\right)$, on primary product yield, that is, benzaldehyde $(\mathrm{BzH})$.

All factors in the experiment were coded into three levels, namely $-1,0$, and +1 as shown in Table 1 . A total of 29 experimental sets, including 24 factorial points and 5 central points, were adopted for the experimental design. Accordingly, the predicted response (product yield; Y) may be expressed as:

$\mathrm{Y}=\beta_{0}+\sum_{\mathrm{i}=1}^{4} \beta_{\mathrm{i}} x_{\mathrm{i}}+\sum_{\mathrm{i}=1}^{4} \beta_{\mathrm{ii}} x_{\mathrm{i}}^{2}+\sum_{\mathrm{i}<\mathrm{j}}^{4} \beta_{\mathrm{ij}} x_{\mathrm{i}} x_{\mathrm{j}}$

where $x_{\mathrm{i}}$ and $x_{\mathrm{j}}(\mathrm{i}, \mathrm{j}=1-4)$ represents the coded levels of various independent variables, and $\beta_{0}, \beta_{\mathrm{i}}, \beta_{\mathrm{ii}}$, and $\beta_{\mathrm{ij}}$ are regression coefficients representing the offset, linear, quadratic, and interactive terms of the variables, respectively.

Table 1. List of symbols for various experimental variables and corresponding coded levels and ranges adopted in the experimental design

\begin{tabular}{lcccc}
\hline \multirow{2}{*}{ Variable } & \multirow{3}{*}{ Symbol } & \multicolumn{3}{c}{ Range and level } \\
\cline { 3 - 5 } & & -1 & 0 & +1 \\
\hline Amount of catalyst / g & $x_{1}$ & 0.7 & 0.8 & 0.9 \\
Alcohol/hydrogen peroxide / $\left(\mathrm{mol} \mathrm{mol}^{-1}\right)$ & $x_{2}$ & $1: 1$ & $1: 2$ & $1: 3$ \\
Reaction time / h & $x_{3}$ & 3 & 4 & 5 \\
Amount of water / $\mathrm{mL}$ & $x_{4}$ & 15 & 20 & 25 \\
\hline
\end{tabular}

Kinetic study

The kinetic parameters associated with conversion of $\mathrm{BzOH}$ were also monitored for the $20 \mathrm{HPW} / \mathrm{CeO}_{2}$ catalyst. By varying the reaction times and temperatures the reaction rate (r) for oxidation of $\mathrm{BzOH}$ with $\mathrm{H}_{2} \mathrm{O}_{2}$ to $\mathrm{BzH}$ may be derived by the equation:

$\mathrm{r}=-\frac{\mathrm{dC}_{\mathrm{A}}}{\mathrm{dt}}=\mathrm{k}^{\prime} \mathrm{C}_{\mathrm{A}}^{\alpha} \mathrm{C}_{\mathrm{B}}^{\beta}$

where $\mathrm{C}_{\mathrm{A}}$ and $\mathrm{C}_{\mathrm{B}}$ represents the concentration of $\mathrm{BzOH}$ and $\mathrm{H}_{2} \mathrm{O}_{2}$, respectively, $\mathrm{k}$ ' is the rate constant, and $\alpha$ and $\beta$ denote the reaction order of $\mathrm{BzOH}$ and $\mathrm{H}_{2} \mathrm{O}_{2}$, respectively. By taking the natural log of both sides, the above equation may further be expressed as:

$\ln r=\ln k+\alpha \ln C_{A}$

where $\mathrm{k}=\mathrm{k}^{\prime} \mathrm{C}_{\mathrm{B}}^{\beta}$ denotes the modified rate constant. By measuring the $\mathrm{k}$ values at various temperatures, the activation energy $\left(\mathrm{E}_{\mathrm{a}}\right)$ could be derived from the Arrhenius equation: $\ln \mathrm{k}=\ln \mathrm{k}_{0}-\frac{\mathrm{E}_{\mathrm{a}}}{\mathrm{R}} \frac{1}{\mathrm{~T}}$

where $\mathrm{k}_{0}$ represents the pre-exponential factor, $\mathrm{R}$ is the gas constant, and $\mathrm{T}$ is the reaction temperature.

\section{Results and Discussion}

\section{Characterization of catalysts}

FTIR spectroscopy is employed to elucidate chemical compositions and local configurations of various catalyst samples. The FTIR spectra of $\mathrm{CeO}_{2}, \mathrm{HPW}$ and $\mathrm{HPW} / \mathrm{CeO}_{2}$ with varied HPW loadings are shown in Figure 1. Similar to the pristine HPW (Figure 1a), the supported $\mathrm{HPW} / \mathrm{CeO}_{2}$ catalysts showed multiple absorption bands between 4000 and $400 \mathrm{~cm}^{-1}$ (Figures 1c-1e). The broad overlapping absorption bands centering at ca. $3435 \mathrm{~cm}^{-1}$ may be ascribed to stretching vibrations of $\mathrm{O}-\mathrm{H}$. The signals at 1080, 983, 889, and $804 \mathrm{~cm}^{-1}$, which may be attributed to asymmetric stretching vibrations of $\mathrm{P}-\mathrm{O}$, terminal vibration of $\mathrm{W}=\mathrm{O}$, corner-sharing $\mathrm{W}-\mathrm{O}_{\mathrm{b}}-\mathrm{W}$, and edgesharing $\mathrm{W}-\mathrm{Oc}-\mathrm{W}$ bonds, respectively, are characteristic bands anticipated for the Keggin-type unit of the $\mathrm{PW}_{12} \mathrm{O}_{40}{ }^{3-}$ (PW) polyanions. ${ }^{39}$ Clearly, these characteristic peaks are absent in the FTIR spectrum observed for the pure $\mathrm{CeO}_{2}$ support (Figure $1 \mathrm{~b}$ ). Moreover, the presence of weaker absorption bands at ca. 598 and $516 \mathrm{~cm}^{-1}$ may be attributed to symmetric vibrations of $\mathrm{O}-\mathrm{P}-\mathrm{O}$ and $\mathrm{W}-\mathrm{O}-\mathrm{W}$, respectively. ${ }^{33}$ Regardless of minor variations in intensities of characteristic bands responsible for the $\mathrm{PW}$ polyanions, their presence in all supported $\mathrm{HPW} / \mathrm{CeO}_{2}$ catalysts confirm that Keggin structure remains intact upon supporting varied

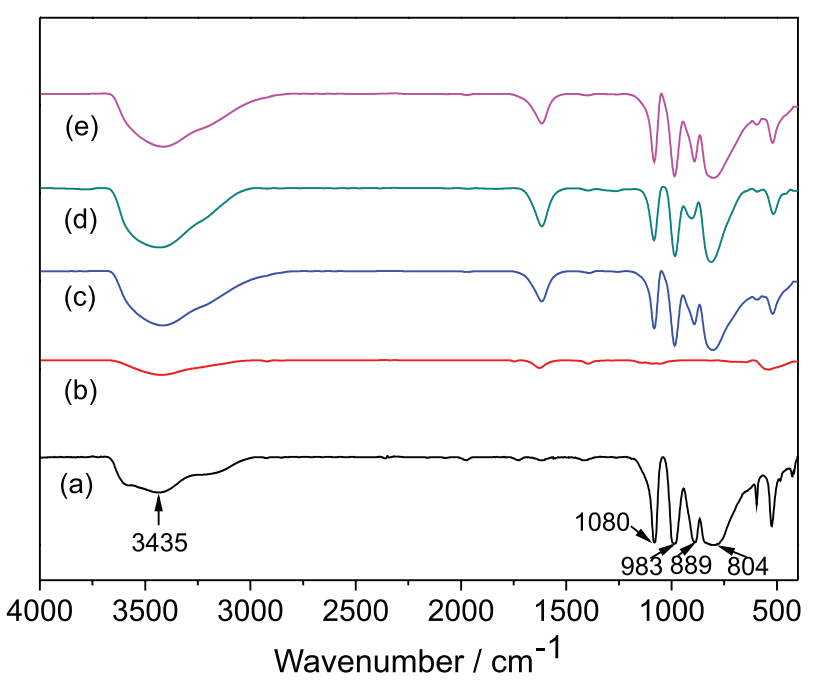

Figure 1. FTIR spectra of (a) the pristine HPW; (b) pure $\mathrm{CeO}_{2}$; (c) $15 \mathrm{HPW} / \mathrm{CeO}_{2}$; (d) $20 \mathrm{HPW} / \mathrm{CeO}_{2}$; and (e) $25 \mathrm{HPW} / \mathrm{CeO}_{2}$. 
amounts of HPW onto the $\mathrm{CeO}_{2}$ support.

The crystalline structures of the pure $\mathrm{CeO}_{2}$, pristine $\mathrm{HPW}$, and various supported $\mathrm{HPW} / \mathrm{CeO}_{2}$ composites with varied HPW loadings were examined by XRD, as shown in Figure 2. The $\mathrm{CeO}_{2}$ support exhibited XRD profile with well-defined diffraction peaks at $2 \theta$ angles of 28.5, 33.4, 46.6, 56.7, 58.0, 69.2, 76.2, and 78.9 (Figure 2a), corresponding to the crystalline lattice planes of (111), (200), (220), (311), (222), (400), (331), and (420), respectively. The above diffraction peaks observed for the as-prepared $\mathrm{CeO}_{2}$ are in excellent agreement with the face center cubic (fcc) phase structure of ceria (JCPDS Card No. 34-394), as expected. On the other hand, the XRD profile of pristine HPW showed characteristic diffraction pattern anticipated for the PW Keggin unit with main peaks at 10.3, 25.3, and $34.6^{\circ}$ (Figure 2b) ${ }^{26,39}$ However, these characteristic features were invisible in various supported $\mathrm{xHPW} / \mathrm{CeO}_{2}(\mathrm{x}=15,20$, and 25 wt.\%) composite materials (Figures 2c-2e). Rather, the XRD profile observed for these supported catalysts were nearly identical with that observed for the as-prepared $\mathrm{CeO}_{2}$ (Figure 2a). The above results suggested that the incorporated HPW are well-dispersed on the surfaces of the $\mathrm{CeO}_{2}$ support. Together with the results obtained from FTIR spectroscopy, it is indicative that HPWs are successfully incorporated and homogeneously dispersed on the $\mathrm{CeO}_{2}$ support.

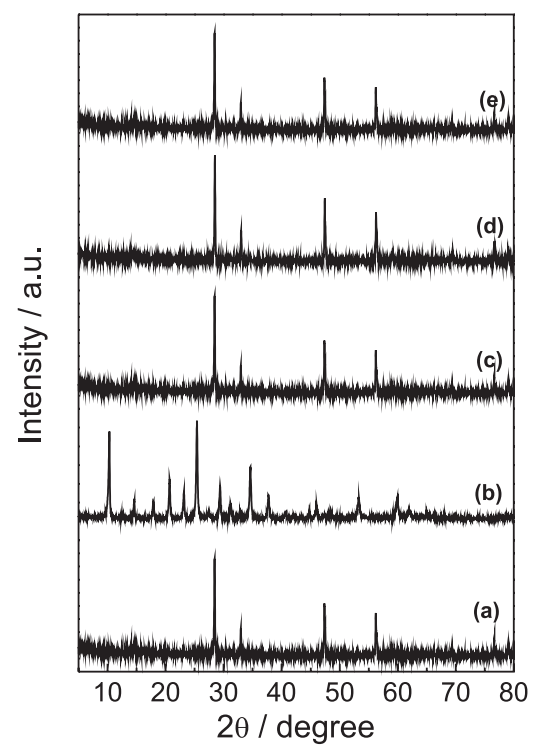

Figure 2. XRD patterns of (a) $\mathrm{CeO}_{2}$; (b) $\mathrm{HPW}$; (c) $15 \mathrm{HPW} / \mathrm{CeO}_{2}$; (d) $20 \mathrm{HPW} / \mathrm{CeO}_{2}$; and (e) $25 \mathrm{HPW} / \mathrm{CeO}_{2}$.

Additional physisorption studies by $\mathrm{N}_{2}$ adsorption/ desorption isotherm measurements have also been made (not shown). Accordingly, the pristine HPW and the pure $\mathrm{CeO}_{2}$ samples gave rise to a BET surface area of 6.8 and $26.0 \mathrm{~m}^{2} \mathrm{~g}^{-1}$, respectively. However, a somewhat anticipated BET surface area of $11.0,8.1$, and $7.5 \mathrm{~m}^{2} \mathrm{~g}^{-1}$ was observed for the $15 \mathrm{HPW} / \mathrm{CeO}_{2}, 20 \mathrm{HPW} / \mathrm{CeO}_{2}$, and $25 \mathrm{HPW} / \mathrm{CeO}_{2}$ catalysts, respectively. The consistent decrease in surface area with increasing HPW loading observed for the supported catalysts provides additional support to the above FTIR and XRD results to verify that the incorporated HPW was indeed nicely dispersed in the porous $\mathrm{CeO}_{2}$ support. ${ }^{40}$

The acid properties of various samples were monitored by solid-state ${ }^{31} \mathrm{P}$ MAS NMR using TMPO as probe molecule, which has been shown to be a powerful and reliable technique for acidity characterization. ${ }^{34,35}$ Such ${ }^{31} \mathrm{P}$-TMPO NMR approach relies on the adsorption of a basic probe molecule TMPO onto the acid catalyst. Then the catalyst shows a desirable NMR-sensitive nuclei (i.e., ${ }^{31} \mathrm{P}$ ) with a broad range chemical shift (denoted as $\delta^{31} \mathrm{P}$ ). As a result, the probe molecule tends to interact with the available Brønsted acidic protons $\left(\mathrm{H}^{+}\right)$site in the acid catalyst to form $\mathrm{TMPOH}^{+}$ complexes with varied values of $\delta^{31} \mathrm{P}$. It has been shown that detailed acid features such as acid types, concentration, distribution, and strength of acid catalysts may readily be determined by means of the ${ }^{31} \mathrm{P}$-TMPO NMR approach. ${ }^{34,35}$ This is made possible by the fact that a linear correlation between the observed $\delta^{31} \mathrm{P}$ and acidic strength may readily be inferred. ${ }^{34-38}$ Moreover, the acid types and concentration may readily be determined by chemical shift assignment and spectral deconvolution of the observed ${ }^{31} \mathrm{P}$ spectrum. Accordingly, the ${ }^{31} \mathrm{P}$ NMR spectra of TMPO adsorbed on various catalysts are depicted in Figure 3. The spectrum observed for TMPO-adsorbed on pure $\mathrm{CeO}_{2}$ revealed broad overlapping signals spanning between $\delta^{31} \mathrm{P}$ of ca. $35-55 \mathrm{ppm}$. The ${ }^{31} \mathrm{P}$ resonance centering at ca. $50 \mathrm{ppm}$ should be due to physisorbed TMPO, whereas those centering at ca. 42 and $36 \mathrm{ppm}$ may be attributed to bulk and mobile TMPO, respectively. As for TMPO adsorbed on the pristine TPA, broad resonances centering at three distinct regions with $\delta^{31} \mathrm{P}$ of -10 to $-15,55$ to 75 , and 80 to $95 \mathrm{ppm}$ were observed (Figure 3e), which may be ascribed due to PW Keggin unit, (TMPO) ${ }_{n} \mathrm{H}^{+}$adducts $(n>1.0)$, and $\mathrm{TMPOH}^{+}$complexes, respectively. ${ }^{34,39}$ It is noteworthy that the catalyst showed superacidity which exceeds the threshold acidic strength for superacidity (86 ppm). ${ }^{34-37,39}$ So the pristine HPW and supported $\mathrm{HPW} / \mathrm{CeO}_{2}$ possess superacidity. Unlike the pristine HPW, an additional peak at ca. $66 \mathrm{ppm}$ was observed for all supported $\mathrm{HPW} / \mathrm{CeO}_{2}$ catalysts (Figures 3b-3d), indicating the presence of Lewis acidity arising from Ce metal centers. ${ }^{34,35}$ Similar phenomenon was also found for HPW incorporated on other metal oxide supports such as $\mathrm{ZrO}_{2}$ and $\mathrm{TiO}_{2}$, as illustrated in Figure 4. Moreover, it is indicative that the overall strength of acid sites (particularly those with $\delta^{31} \mathrm{P}>80 \mathrm{ppm}$ ) of the supported $\mathrm{HPW} / \mathrm{CeO}_{2}$ catalysts follow the ascending trend: $15 \mathrm{HPW} / \mathrm{CeO}_{2}<20 \mathrm{HPW} / \mathrm{CeO}_{2}<25 \mathrm{HPW} / \mathrm{CeO}_{2}$. Thus, it is 


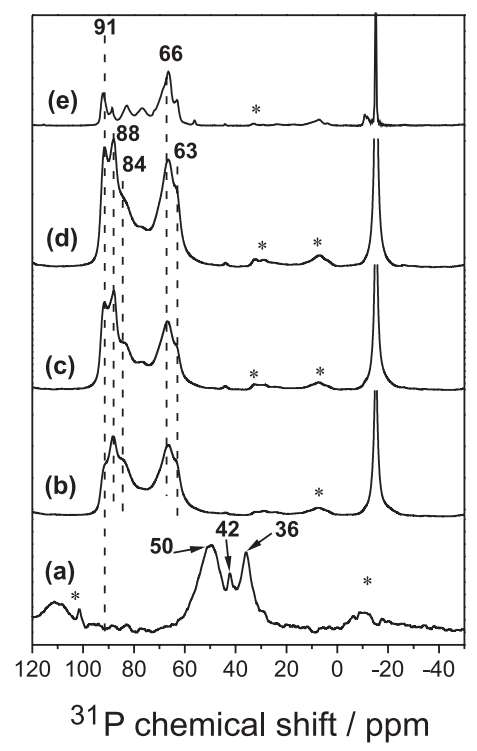

Figure 3. ${ }^{31} \mathrm{P}$ NMR spectra of TMPO adsorbed on (a) $\mathrm{CeO}_{2}$; (b) $15 \mathrm{HPW} / \mathrm{CeO}_{2}$; (c) $20 \mathrm{HPW} / \mathrm{CeO}_{2}$; (d) $25 \mathrm{HPW} / \mathrm{CeO}_{2}$; (e) pristine HPW. Asterisks represent spinning sidebands.

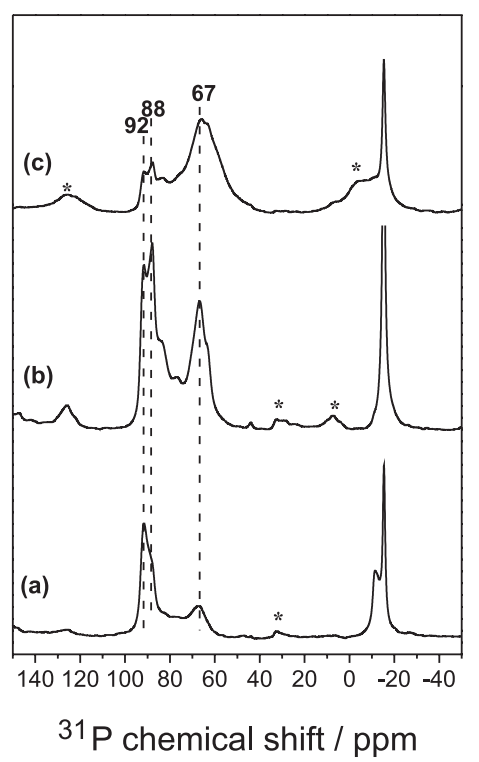

Figure 4. ${ }^{31} \mathrm{P}$ NMR spectra of TMPO adsorbed on (a) $20 \mathrm{HPW} / \mathrm{ZrO}_{2}$; (b) $20 \mathrm{HPW} / \mathrm{CeO}_{2}$; and (c) $20 \mathrm{HPW} / \mathrm{TiO}_{2}$. Asterisks represent spinning sidebands. indicative that the incorporation of superacidic HPW onto the $\mathrm{CeO}_{2}$ support tends to provoke formation of Lewis acidity. Together with the ultra-strong Brønsted acidity, a synergy effect due to Brønsted-Lewis acid sites may be inferred for the satisfying catalytic performance observed for the supported $\mathrm{HPW} / \mathrm{CeO}_{2}$ catalysts during oxidation of $\mathrm{BzOH}$ (vide infra).

\section{Oxidation of benzyl alcohol to benzaldehyde}

Table 2 summarizes the catalytic performances of various catalysts during oxidation of $\mathrm{BzOH}$. The $\mathrm{CeO}_{2}$ support, which possesses the weakest acidity, exhibited null activity for oxidation of $\mathrm{BzOH}$. Upon incorporation of HPW onto $\mathrm{CeO}_{2}$, a significant enhancement in catalytic activity was observed. The $15 \mathrm{HPW} / \mathrm{CeO}_{2}$ catalyst with $\mathrm{HPW}$ loading of $15 \mathrm{wt} . \%$ showed satisfactory $\mathrm{BzOH}$ conversion and $\mathrm{BzH}$ product yield of 77.9 and $76.0 \%$, respectively. Upon increasing the HPW loading to $20 \mathrm{wt} . \%$, notable increases in both $\mathrm{BzOH}$ conversion $(94.0 \%)$ and $\mathrm{BzH}$ yield (92.3\%) with excellent selectivity (98.2\%) were observed. However, further increase in HPW loading to $25 \mathrm{wt} . \%$ led to inferior performance, the $\mathrm{BzOH}$ conversion and $\mathrm{BzH}$ yield decreased to 93.2 and $88.4 \%$, respectively. The effect of support on $\mathrm{BzOH}$ oxidation were also investigated, and the results obtained from 20 wt.\% HPW on $\mathrm{ZrO}_{2}, \mathrm{TiO}_{2}$ and $\mathrm{CeTiO}$ supports are also depicted in Table 2. Even though $\mathrm{CeTiO}, \mathrm{TiO}_{2}$ and $\mathrm{ZrO}_{2}$ were found to have a larger surface area (94, 53 and $33 \mathrm{~m}^{2} \mathrm{~g}^{-1}$, respectively) than $\mathrm{CeO}_{2}$ $\left(8.1 \mathrm{~m}^{2} \mathrm{~g}^{-1}\right)$, it is obvious that the $20 \mathrm{HPW} / \mathrm{CeO}_{2}$ catalyst still outperformed its counterparts for oxidation of $\mathrm{BzOH}$.

The satisfying catalytic performance observed for the $20 \mathrm{HPW} / \mathrm{CeO}_{2}$ catalyst during oxidation of $\mathrm{BzOH}$ with $\mathrm{H}_{2} \mathrm{O}_{2}$ may be correlated to its acid properties, as evidenced by results obtained from ${ }^{31} \mathrm{P}$ MAS NMR of adsorbed TMPO (Figures 3 and 4) discussed above. Clearly, the presence of excessive amount of ultra-strong acidity is detrimental for oxidation of alcohol. As such, the satisfying catalytic

Table 2. Comparisons of catalytic performances over various catalysts during oxidation of benzyl alcohol ${ }^{\mathrm{a}}$

\begin{tabular}{lccc}
\hline Catalyst & $\mathrm{BzOH}$ conversion $/ \%$ & $\mathrm{BzH}$ selectivity / \% & $\mathrm{BzH}$ yield / \% \\
\hline $\mathrm{CeO}_{2}$ & nil & nil & nil \\
$15 \mathrm{HPW} / \mathrm{CeO}_{2}$ & 77.9 & 97.6 & 76.0 \\
$20 \mathrm{HPW} / \mathrm{CeO}_{2}$ & 94.0 & 98.2 & 92.3 \\
$25 \mathrm{HPW} / \mathrm{CeO}_{2}$ & 93.2 & 94.7 & 88.4 \\
$20 \mathrm{HPW} / \mathrm{TiO}_{2}$ & 84.0 & 96.6 & 81.2 \\
$20 \mathrm{HPW} / \mathrm{ZrO}_{2}$ & 90.8 & 91.7 & 83.3 \\
$20 \mathrm{HPW} / \mathrm{CeTiO}^{\mathrm{b}}$ & 89.3 & 93.2 & 83.2 \\
\hline
\end{tabular}

${ }^{a}$ Reactions were performed under the conditions: $\mathrm{BzOH} / \mathrm{H}_{2} \mathrm{O}_{2}, 1: 2\left(\mathrm{~mol} \mathrm{~mol}^{-1}\right)$; amount of catalyst, $0.8 \mathrm{~g}$; reaction time, $4 \mathrm{~h}$; amount of water, $20 \mathrm{~mL}$; temperature, $110{ }^{\circ} \mathrm{C} ;{ }^{\text {b }} \mathrm{CeTiO}$ was prepared by sol-gel method. 
activity observed for the $20 \mathrm{HPW} / \mathrm{CeO}_{2}$ catalyst may be attributed to the presence of desirable amount of strong Brønsted and Lewis acid sites. In other word, it is due to a synergetic effect of Brønsted-Lewis acid sites. Since the $20 \mathrm{HPW} / \mathrm{CeO}_{2}$ catalyst exhibited the best catalytic performance for oxidation of $\mathrm{BzOH}$ to $\mathrm{BzH}$, it was exploited for the subsequent process variable optimization and kinetic studies.

\section{Effects of reaction parameters on oxidation of benzyl alcohol}

The effects of experimental parameters such as amount of catalyst, reaction time, temperature, $\mathrm{BzOH} / \mathrm{H}_{2} \mathrm{O}_{2}$ molar ratio, and amount of water on catalytic performances during the oxidation reaction over the $20 \mathrm{HPW} / \mathrm{CeO}_{2}$ catalyst were studied. This is done by varying a target parameter while keeping the others fixed, as shown Figure 5. Both $\mathrm{BzOH}$ conversion and $\mathrm{BzH}$ yield increases with increasing
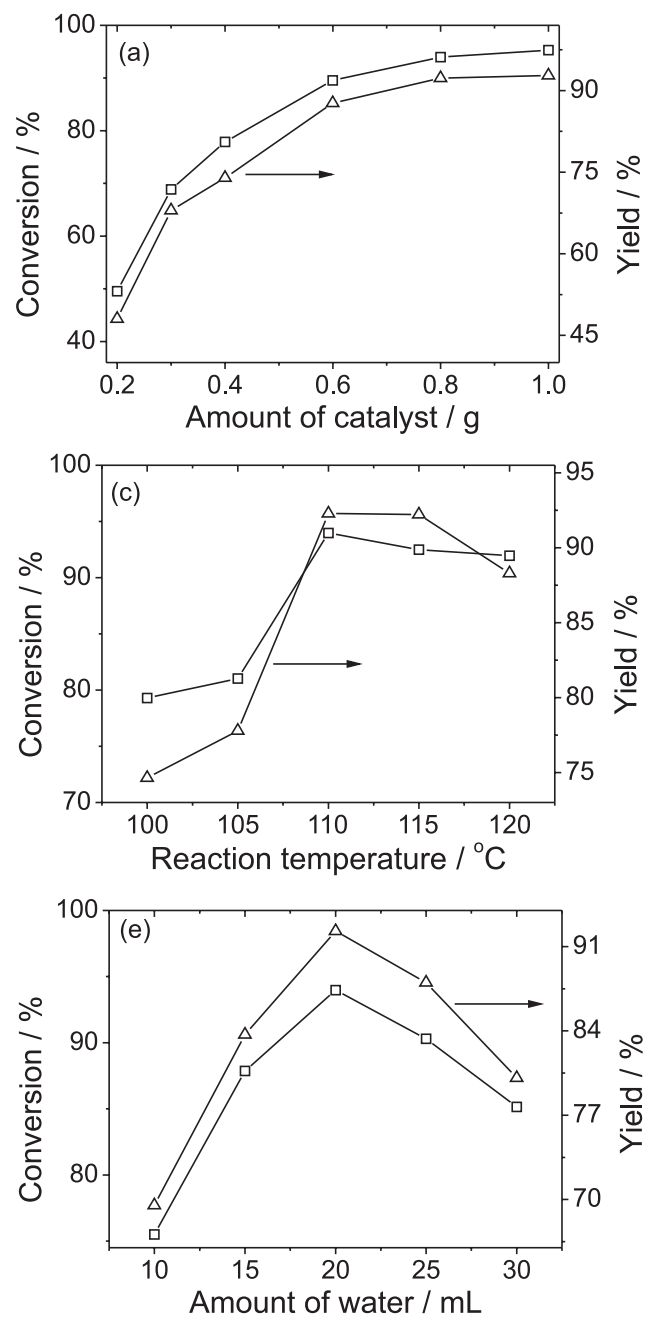

catalyst amount (Figure 5a), reaching a plateau at ca. $0.8 \mathrm{~g}$ with a conversion and product yield of 94.0 and $92.3 \%$, respectively. It is expected that more amount of catalyst in the reaction system warrants more available active moieties for catalyzing the reaction. Nevertheless, upon reacting a desirable amount of active moieties required for oxidation of $\mathrm{BzOH}$, further increase in catalyst amount is redundant. Likewise, an optimal reaction time of $4 \mathrm{~h}$ (Figure 5b), reaction temperature of $110{ }^{\circ} \mathrm{C}$ (Figure 5c), $\mathrm{BzOH} / \mathrm{H}_{2} \mathrm{O}_{2}$ ratio of 1:2 (Figure $5 \mathrm{~d}$ ), and amount of water of $20 \mathrm{~mL}$ (Figure 5e) may also be inferred. It is anticipated that reaction carried out over extended period of time and elevated temperatures may provoke occurrence of undesirable side reactions. Moreover, a desirable excessive amounts of $\mathrm{H}_{2} \mathrm{O}_{2}$ and water is favorable for driving the equilibrium towards formation of $\mathrm{BzH}$, whilst an immense amount of $\mathrm{H}_{2} \mathrm{O}_{2}$ tends to dilute the reaction system, which is unfavorable for BzH selectivity and yield. The presence
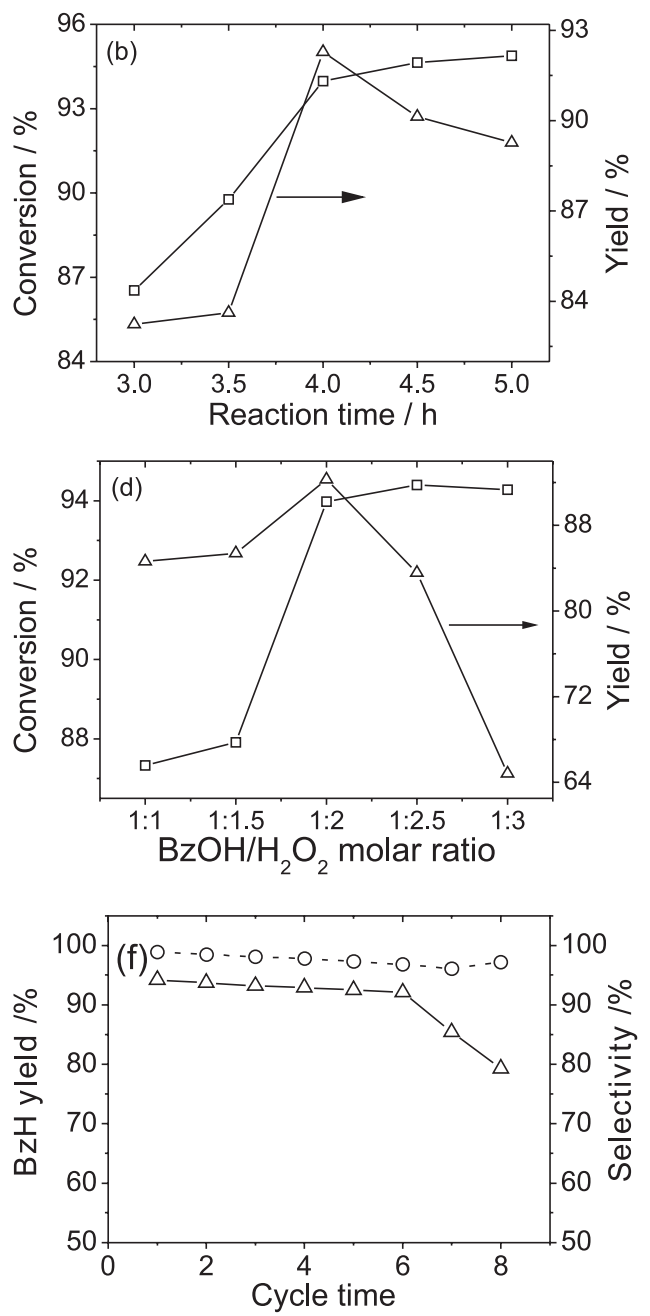

Figure 5. Effects of (a) amount of catalyst; (b) reaction time; (c) reaction temperature; (d) benzyl alcohol (BzOH) to hydrogen peroxide $\left(\mathrm{H}_{2} \mathrm{O}_{2}\right)$ molar ratio; and (e) amount of water on conversion $(\square)$ and benzaldehyde yield $(\triangle)$ during oxidation of $\mathrm{BzOH}$ with $\mathrm{H}_{2} \mathrm{O}_{2}$ over the $20 \mathrm{HPW} / \mathrm{CeO}_{2}$ catalyst; (f) recyclability test. Unless otherwise specified, all reactions were performed under the typical conditions: amount of catalyst, $0.8 \mathrm{~g} ; \mathrm{BzOH} / \mathrm{H}_{2} \mathrm{O}_{2}, 1: 1.2\left(\mathrm{~mol} \mathrm{~mol}{ }^{-1}\right)$; reaction time, $4.0 \mathrm{~h}$; amount of water, $20.0 \mathrm{~mL}$; temperature, $110^{\circ} \mathrm{C}$. 
of water tends to form special droplets in the heterogeneous reaction system to favor adsorption and/or activation of oxidant during the oxidation reaction. Thus, it is conclusive that the best performance for efficient oxidation of $\mathrm{BzOH}$ with $\mathrm{H}_{2} \mathrm{O}_{2}$ over the $20 \mathrm{HPW} / \mathrm{CeO}_{2}$ catalyst may be obtained under the optimal experimental conditions: $\mathrm{BzOH} / \mathrm{H}_{2} \mathrm{O}_{2}$, 1:2 (mol mol-1); reaction time, $4.0 \mathrm{~h}$; amount of catalyst, $0.8 \mathrm{~g}$; amount of water, $20.0 \mathrm{~mL}$; and reaction temperature, $110{ }^{\circ} \mathrm{C}$. As a result, a maximum $\mathrm{BzOH}$ conversion of $94.0 \%$ and a BzH selectivity and yield of 98.2 and $92.3 \%$, respectively, may be achieved.

\section{RSM and ANOVA studies}

A factorial analysis by analysis of variance (ANOVA) and response surface methodology (RSM) were utilized to investigate the interactive effects between experimental variables and to optimize process variables. Accordingly, the product yields $(\mathrm{Y})$ predicted by multiple regression analysis may be predicted by means of a quadratic model:

$\mathrm{Y}=92.28+6.17 x_{1}+2.13 x_{2}+2.79 x_{3}+1.99 x_{4}-5.70 x_{1}^{2}-$ $3.41 x_{2}{ }^{2}-2.00 x_{3}{ }^{2}-2.58 x_{4}{ }^{2}-1.33 x_{1} x_{2}-3.15 x_{1} x_{3}+0.19 x_{1} x_{4}$ $-2.34 x_{2} x_{3}-2.49 x_{2} x_{4}+0.22 x_{3} x_{4}$

where $x_{1}, x_{2}, x_{3}$, and $x_{4}$ represent the coded values of the four process variables defined in Table 1, and the results are summarized in Table 3.

By fitting the experimental results with those predicted by RSM, the reliability of the fitting and validity of the proposed model in equation 5 may be assessed. As depicted in Table 4, a coefficient of determination $\left(\mathrm{R}^{2}\right)$ value of 0.9811 was achieved, revealing that only a minimal percentage $(1.9 \%)$ of the fittings were unjustifiable by the model. Moreover, an $F_{\text {model }}$ value of 51.87 and a lack-of-fit of 3.78 were obtained, implying the lack-of-fit is not significant relative to the pure error. These results indicate that the proposed model was adequate and the fittings between the experimental and predicted results are highly reliable.

Based on the RSM results, the correlations between process variable pairs for oxidation of $\mathrm{BzOH}$ with $\mathrm{H}_{2} \mathrm{O}_{2}$ over the $20 \mathrm{HPW} / \mathrm{CeO}_{2}$ catalyst may further be clarified by the contour plots and three-dimensional (3D) response surface plots shown in Figures S1 and S2 of the Supplementary Information, respectively. It was found that the correlations between catalyst loading $\left(x_{1}\right)$ and $\mathrm{BzOH} / \mathrm{H}_{2} \mathrm{O}_{2}$ molar ratio $\left(x_{2}\right)$, and that of reaction time $\left(x_{3}\right)$ and water amount $\left(x_{4}\right)$ on BzH yield were not significant, as evidenced by the nearly circular contour plots in Figures S1a and S1f. On the other hand, the elliptical shape of the contour plots in
Table 3. List of experimental design and response values obtained for oxidation of $\mathrm{BzOH}$ over the $20 \mathrm{HPW} / \mathrm{CeO}_{2}$ catalyst

\begin{tabular}{|c|c|c|c|c|c|}
\hline \multirow{2}{*}{ entry } & \multicolumn{4}{|c|}{ Variable and level } & \multirow{2}{*}{ Yield / \% } \\
\hline & $x_{1}$ & $x_{2}$ & $x_{3}$ & $x_{4}$ & \\
\hline 1 & -1 & -1 & 0 & 0 & 73.00 \\
\hline 2 & 1 & -1 & 0 & 0 & 88.15 \\
\hline 3 & -1 & 1 & 0 & 0 & 80.98 \\
\hline 4 & 1 & 1 & 0 & 0 & 90.82 \\
\hline 5 & 0 & 0 & -1 & -1 & 84.55 \\
\hline 6 & 0 & 0 & 1 & -1 & 88.23 \\
\hline 7 & 0 & 0 & -1 & 1 & 86.86 \\
\hline 8 & 0 & 0 & 1 & 1 & 91.41 \\
\hline 9 & -1 & 0 & 0 & -1 & 75.38 \\
\hline 10 & 1 & 0 & 0 & -1 & 88.50 \\
\hline 11 & -1 & 0 & 0 & 1 & 80.24 \\
\hline 12 & 1 & 0 & 0 & 1 & 94.13 \\
\hline 13 & 0 & -1 & -1 & 0 & 80.17 \\
\hline 14 & 0 & 1 & -1 & 0 & 88.09 \\
\hline 15 & 0 & -1 & 1 & 0 & 91.47 \\
\hline 16 & 0 & 1 & 1 & 0 & 90.03 \\
\hline 17 & -1 & 0 & -1 & 0 & 72.34 \\
\hline 18 & 1 & 0 & -1 & 0 & 89.63 \\
\hline 19 & -1 & 0 & 1 & 0 & 84.61 \\
\hline 20 & 1 & 0 & 1 & 0 & 89.31 \\
\hline 21 & 0 & -1 & 0 & -1 & 79.08 \\
\hline 22 & 0 & 1 & 0 & -1 & 88.30 \\
\hline 23 & 0 & -1 & 0 & 1 & 88.02 \\
\hline 24 & 0 & 1 & 0 & 1 & 87.29 \\
\hline 25 & 0 & 0 & 0 & 0 & 91.61 \\
\hline 26 & 0 & 0 & 0 & 0 & 91.70 \\
\hline 27 & 0 & 0 & 0 & 0 & 93.00 \\
\hline 28 & 0 & 0 & 0 & 0 & 92.11 \\
\hline 29 & 0 & 0 & 0 & 0 & 93.00 \\
\hline
\end{tabular}

Figures S1d and S1e revealed that correlations between $x_{2}\left(\mathrm{BzOH} / \mathrm{H}_{2} \mathrm{O}_{2}\right.$ molar ratio) and $x_{3}$ (reaction time) and $x_{4}$ (water amount) were more significant. Moreover, it is obvious that the most significant effect on BzH yield arose from interactions between amount of catalyst $\left(x_{1}\right)$ and reaction time $\left(x_{3}\right)$, as shown in Figures S1b and S2b (Supplementary Information). The above observations are consistent with the ANOVA results depicted in Table 4 and coincide with the smaller coefficient observed for the $x_{1} x_{4}$ $(0.19)$ and $x_{3} x_{4}(0.22)$ interactive terms in equation 5 .

Based on results obtained from RSM, the optimized reaction conditions for most effective oxidation of $\mathrm{BzOH}$ with $\mathrm{H}_{2} \mathrm{O}_{2}$ over the $20 \mathrm{HPW} / \mathrm{CeO}_{2}$ catalyst may be 
Table 4. List of results obtained from ANOVA for BzH yield

\begin{tabular}{|c|c|c|c|c|c|c|}
\hline Source & Sum of square & DF & Mean square & $F$ & $P>F$ & Significance \\
\hline Model & 1002.33 & 14 & 71.60 & 51.87 & $<0.0001$ & a \\
\hline$x_{1}$ & 456.21 & 1 & 456.21 & 330.52 & $<0.0001$ & $\mathrm{a}$ \\
\hline$x_{2}$ & 54.70 & 1 & 54.70 & 39.63 & $<0.0001$ & a \\
\hline$x_{3}$ & 93.07 & 1 & 93.07 & 67.43 & $<0.0001$ & $\mathrm{a}$ \\
\hline$x_{4}$ & 47.64 & 1 & 47.64 & 34.52 & $<0.0001$ & a \\
\hline$x_{1}^{2}$ & 210.52 & 1 & 210.52 & 152.52 & $<0.0001$ & a \\
\hline$x_{2}^{2}$ & 75.35 & 1 & 75.35 & 54.59 & $<0.0001$ & a \\
\hline$x_{3}^{2}$ & 25.84 & 1 & 25.84 & 18.72 & 0.0007 & a \\
\hline$x_{4}^{2}$ & 43.33 & 1 & 43.33 & 31.39 & $<0.0001$ & a \\
\hline$x_{1} x_{2}$ & 7.05 & 1 & 7.05 & 5.11 & 0.0403 & $\mathrm{~b}$ \\
\hline$x_{1} x_{3}$ & 39.63 & 1 & 39.63 & 28.71 & 0.0001 & a \\
\hline$x_{1} x_{4}$ & 0.15 & 1 & 0.15 & 0.11 & 0.7480 & \\
\hline$x_{2} x_{3}$ & 21.90 & 1 & 21.90 & 15.87 & 0.0014 & a \\
\hline$x_{2} x_{4}$ & 24.75 & 1 & 24.75 & 17.93 & 0.0008 & a \\
\hline$x_{3} x_{4}$ & 0.19 & 1 & 0.19 & 0.14 & 0.7167 & \\
\hline Residual & 19.32 & 14 & 1.38 & & & \\
\hline Lack-of-fit & 17.47 & 10 & 1.75 & 3.78 & 0.1061 & NS \\
\hline Pure error & 1.85 & 4 & 0.46 & & & \\
\hline Cor. total & 1021.66 & 28 & & & & \\
\hline
\end{tabular}

DF: degree of freedom; NS: non-significant; ahighly significant; 'significant.

derived as the following: amount of catalyst $\left(x_{1}\right)=0.84 \mathrm{~g}$, $\mathrm{BzOH} / \mathrm{H}_{2} \mathrm{O}_{2}$ ratio $\left(x_{2}\right)=1: 1.19 \mathrm{~mol} \mathrm{~mol}^{-1}$, reaction time $\left(x_{3}\right)=4.43 \mathrm{~h}$, and amount of water $\left(x_{4}\right)=22.31 \mathrm{~mL}$, leading to a predicted $\mathrm{BzH}$ yield of $94.6 \%$. These theoretical results are in excellent agreement with the experimental data. To further verify the validity of the predicted BzH yield, three parallel experiments were carried out independently over the $20 \mathrm{HPW} / \mathrm{CeO}_{2}$ catalyst using these predicted reaction variables. As a result, an experimental BzH yield of $94.2 \%$ was achieved (with $\mathrm{BzOH}$ conversion of $95.2 \%$ and $\mathrm{BzH}$ selectivity of $98.9 \%$ ), in excellent agreement with the predicted yield (94.6\%).

\section{Catalyst recycling test}

The durability and reusability of the $20 \mathrm{HPW} / \mathrm{CeO}_{2}$ catalyst for oxidation of $\mathrm{BzOH}$ with $\mathrm{H}_{2} \mathrm{O}_{2}$ under the simplified process conditions, viz. amount of catalyst $=0.84 \mathrm{~g}$, $\mathrm{BzOH} / \mathrm{H}_{2} \mathrm{O}_{2}$ molar ratio $=1: 1.2 \mathrm{~mol} \mathrm{~mol}{ }^{-1}$, reaction time $=4.4 \mathrm{~h}$, and amount of water $=22.3 \mathrm{~mL}$, were further tested for six consecutive experimental runs. Note that, upon completion of each run, the catalyst was filtered and washed (by diethyl ether) and reused after drying under vacuum for $8 \mathrm{~h}$ at $70{ }^{\circ} \mathrm{C}$. As shown in Figure 5f, the $20 \mathrm{HPW} / \mathrm{CeO}_{2}$ catalyst exhibited good reusability. The $\mathrm{BzH}$ yield and selectivity $\mathrm{BzH}$ decreased from ca. 94.2 and $98.9 \%$ of the initial cycle to ca. 92.1 and $96.8 \%$ of the $6^{\text {th }}$ cycle, respectively. Additional FTIR measurements also revealed that the structural integrity of the $20 \mathrm{HPW} / \mathrm{CeO}_{2}$ catalyst remained practically unchanged for the spent catalyst obtained after six consecutive runs (Figure S3; Supplementary Information). However, the yield of BzH was decreased largely to 85.4 and $79.3 \%$ for the $7^{\text {th }}$ and $8^{\text {th }}$ cycle, respectively. The decrease in catalytic activity observed during cyclic tests may be attributed to the loss of HPW during the regeneration treatment; as evidenced by elemental analyses using the inductively coupled plasma (ICP) technique (ICP-OES CID spectrometer, ICAP 6500; Thermo Scientific). It was found that the overall concentration of $\mathrm{P}$ atom decreased from $0.21 \mathrm{wt} . \%$ of the fresh catalyst to $0.13 \mathrm{wt} . \%$ of the regenerated spent catalyst obtained after eight running cycles. In spite of this drawback, the above results clearly indicate that the $20 \mathrm{HPW} / \mathrm{CeO}_{2}$ catalyst is indeed robust and durable for catalytic oxidation reaction, thus, render practical industrial applications.

\section{Kinetic study}

The kinetic parameters involved during catalytic oxidation of $\mathrm{BzOH}$ over the $20 \mathrm{HPW} / \mathrm{CeO}_{2}$ catalyst were 
also determined. As shown in Figure 6a, by monitoring $\mathrm{BzOH}$ conversion with varied initial concentrations (i.e., $\mathrm{C}_{\mathrm{A}}$ ), the corresponding value of reaction rate ( $\mathrm{r}$ ) may be obtained based on equation 2 , while the reaction order of $\mathrm{BzOH}(\alpha)$ may be derived by equation 3 , as shown in Figure $6 \mathrm{~b}$. As a result, an $\alpha$ value of 1.73 was obtained with a satisfactory correlation coefficient $\left(\mathrm{R}^{2}\right)$ of 0.996 . Likewise, by varying the initial concentrations of $\mathrm{H}_{2} \mathrm{O}_{2}$ (i.e., $\mathrm{C}_{\mathrm{B}}$ ), an $\mathrm{H}_{2} \mathrm{O}_{2}$ reaction order $(\beta)$ of 0.38 with $\mathrm{R}^{2}=0.999$ was obtained, as seen in Figure 7.

Moreover, by plotting the variations of $\mathrm{BzOH}$ concentration (i.e., $\mathrm{C}_{\mathrm{A}}$ ) versus reaction time during oxidation of $\mathrm{BzOH}$ over the $20 \mathrm{HPW} / \mathrm{CeO}_{2}$ catalyst under the optimized reaction conditions (namely, amount of catalyst $=0.84 \mathrm{~g}, \mathrm{BzOH} / \mathrm{H}_{2} \mathrm{O}_{2}=1: 1.2 \mathrm{~mol} \mathrm{~mol}{ }^{-1}$, reaction time $4.4 \mathrm{~h}$, and amount of water of $22.3 \mathrm{~mL}$ ), the rate constants at different reaction temperatures may be obtained, as shown in Figure 8a. Accordingly, based on equation 4, the Arrhenius plot of $\ln \mathrm{k} v s .1 / \mathrm{T}$ in Figure $8 \mathrm{~b}$ may be used to derive the activation energy (Ea) of the reaction, which is $44.7 \mathrm{~kJ} \mathrm{~mol}^{-1}$. Overall, the rate equation for oxidation of $\mathrm{BzOH}$ with $\mathrm{H}_{2} \mathrm{O}_{2}$ over the $20 \mathrm{HPW} / \mathrm{CeO}_{2}$ catalyst may readily be written as:

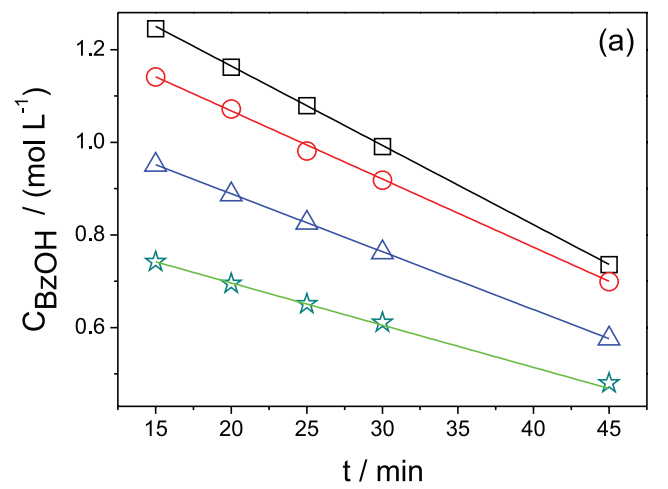

$r=-\frac{\mathrm{dC}_{\mathrm{A}}}{\mathrm{dt}}=\mathrm{e}^{9.6\left(-\frac{44.7}{\mathrm{RT}}\right)} \mathrm{C}_{\mathrm{A}}^{1.7} \mathrm{C}_{\mathrm{B}}^{0.4}$

It is noteworthy that the $\mathrm{E}_{\mathrm{a}}$ value obtained for the present catalytic system for oxidation of $\mathrm{BzOH}$ is much lower than that for oxidation of substituted phenethyl alcohols over the $N$-chlorinated $p$-toluenesulfonamide ( $p$-TSA) salt $\left(81.3 \mathrm{~kJ} \mathrm{~mol}^{-1}\right)^{41}$ and for the oxidation of furfuryl alcohol over heterogeneous nano zirconium chromate catalyst in THF $\left(76.7 \mathrm{~kJ} \mathrm{~mol}^{-1}\right) .^{42}$ This indicates that the $20 \mathrm{HPW} / \mathrm{CeO}_{2}$ catalyst is indeed a highly effective catalyst for oxidation of benzyl alcohol to benzaldehyde.

\section{Conclusions}

Composite catalysts synthesized by incorporating the superacidic tungstophosphoric acid (HPW) on a ceria $\left(\mathrm{CeO}_{2}\right)$ support have been successfully prepared and exploited for oxidation of benzyl alcohol $(\mathrm{BzOH})$ with hydrogen peroxide $\left(\mathrm{H}_{2} \mathrm{O}_{2}\right)$. Among various composite catalysts examined, the catalyst of $20 \mathrm{HPW} / \mathrm{CeO}_{2}$ loaded with 20 wt.\% of HPW was found to exhibit satisfying catalytic activity with excellent $\mathrm{BzOH}$ conversion (94.0\%)

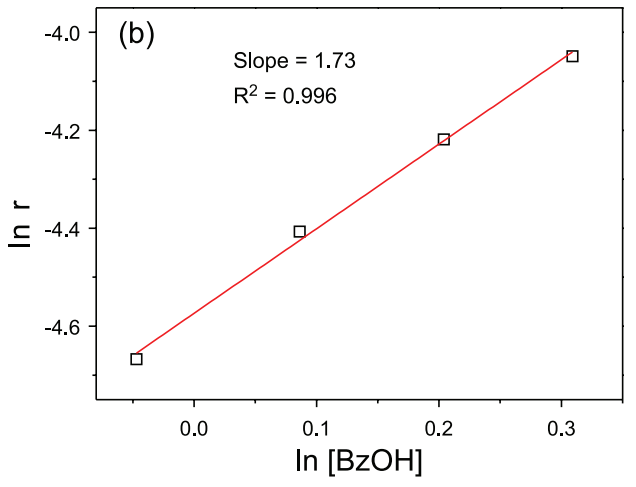

Figure 6. (a) Variations of $\mathrm{BzOH}$ concentration $\left(\mathrm{C}_{\mathrm{A}}\right)$ versus reaction time; symbols for initial $\mathrm{C}_{\mathrm{A}}$ values: $1.36(\square), 1.23(\mathrm{O}), 1.09(\triangle)$, and $0.95 \mathrm{~mol} \mathrm{~L}^{-1}(\hat{\sim})$; (b) $\log -\log$ plot of initial oxidation rate $(\mathrm{r}) v s$. initial $\mathrm{C}_{\mathrm{A}}$. Reaction conditions: temperature, $110{ }^{\circ} \mathrm{C}$; initial $\mathrm{H}_{2} \mathrm{O}_{2}$ concentration, $2.73 \mathrm{~mol} \mathrm{~L}-1$; initial $\mathrm{BzH}$ concentration, $0 \mathrm{~mol} \mathrm{~L}^{-1}$; amount of catalyst, $22.22 \mathrm{~g} \mathrm{~L}^{-1}$.
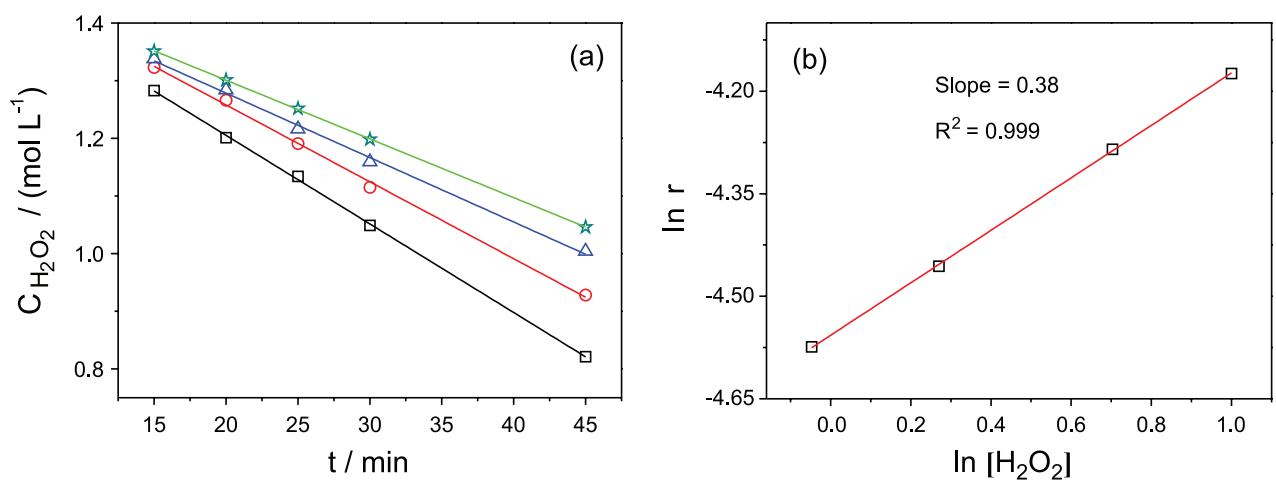

Figure 7. (a) Variations of $\mathrm{H}_{2} \mathrm{O}_{2}$ concentration $\left(\mathrm{C}_{\mathrm{B}}\right)$ versus reaction time; symbols for initial $\mathrm{C}_{\mathrm{B}}$ values: $2.72(\square), 2.02(\mathrm{O}), 1.31(\triangle)$, and $0.95 \mathrm{~mol} \mathrm{~L} \mathrm{~L}^{-1}(\boldsymbol{\varsigma})$; (b) $\log -\log$ plot of initial oxidation rate $v s$. initial $\mathrm{C}_{\mathrm{B}}$. Reaction conditions: temperature, $110{ }^{\circ} \mathrm{C}$; initial $\mathrm{BzOH}$ concentration, $1.36 \mathrm{~mol} \mathrm{~L}^{-1}$; initial $\mathrm{H}_{2} \mathrm{O}_{2}$ concentration, $0 \mathrm{~mol} \mathrm{~L}^{-1}$; amount of catalyst, $22.22 \mathrm{~g} \mathrm{~L}^{-1}$. 

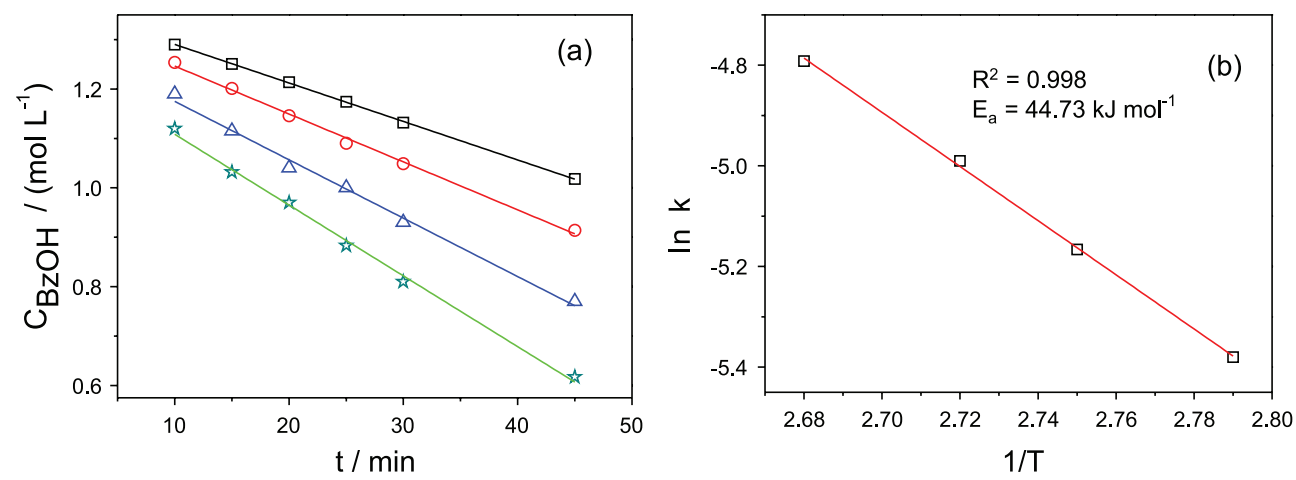

Figure 8. (a) Variations of $\mathrm{BzOH}$ concentration versus reaction time under different reaction temperatures: $95(\square), 100(\bigcirc), 105(\triangle)$, and $110{ }^{\circ} \mathrm{C}(\hat{\zeta})$; (b) the corresponding Arrhenius plot; reaction conditions: initial BzOH concentration, $1.36 \mathrm{~mol} \mathrm{~L}^{-1}$; initial $\mathrm{H}_{2} \mathrm{O}_{2}$ concentration, 2.73 mol L-1; amount of catalyst, $22.22 \mathrm{~g} \mathrm{~L}^{-1}$.

and BzH yield (92.3\%) and selectivity (98.2\%). The satisfying catalytic activity observed for the composite catalyst is attributed to the strong acidity and BrønstedLewis acid synergy effect. Process optimization based on RSM rendered prediction of optimized reaction parameters, namely, amount of catalyst $0.84 \mathrm{~g}, \mathrm{BzOH} / \mathrm{H}_{2} \mathrm{O}_{2}$ ratio $1: 2 \mathrm{~mol} \mathrm{~mol}^{-1}$, reaction time $4.4 \mathrm{~h}$, and amount of water $22.3 \mathrm{~mL}$ at a reaction temperature of $110^{\circ} \mathrm{C}$. Accordingly, the value of $\mathrm{BzOH}$ conversion, $\mathrm{BzH}$ yield, and $\mathrm{BzH}$ selectivity of $95.2,94.2$, and $98.9 \%$, respectively, were derived, in good agreement with the experimental results. Such supported $\mathrm{HPW} / \mathrm{CeO}_{2}$ catalysts, which are cost-effective and may be easily prepared in mass quantity, also exhibit excellent activity, durability, and recyclability, showing prospective applications for large-scale oxidation of alcohols.

\section{Supplementary Information}

Supplementary data associated with this article can be found, in the online version, at http://jbcs.sbq.org.br as PDF file.

\section{Acknowledgments}

The supports of this work by the Project of Science and Technology Department of Zhejiang Province (No. 2016C31016), the Program for Zhejiang Leading Team of S \& T Innovation (No. 2013TD07), and the Ministry of Science and Technology, Taiwan (NSC 104-2113-M-001019) are gratefully acknowledged.

\section{References}

1. Xu, C.; Zhang, C.; Li, H.; Zhao, X.; Song, L.; Li, X.; Catal. Surv. Asia 2016, 20, 13.

2. Du, Y. Y.; Wang, Q.; Liang, X.; He, Y. F.; Feng, J. T.; Li, D. Q.; J. Catal. 2015, 331, 154.
3. Choudhary, V. R.; Jha, R.; Jana, P.; Green Chem. 2007, 9, 267.

4. Friedrich, H. B.; Platinum Met. Rev. 1999, 43, 94.

5. Enache, D. I.; Edwards, J. K.; Landon, P.; Solsona-Espriu, B.; Carley, A. F.; Herzing, A. A.; Watanabe, M.; Kiely, C. J.; Knight, D. W.; Hutchings, G. J.; Science 2006, 311, 362.

6. Cortés Corberán, V.; González-Pérez, M. E.; MartínezGonzález, S.; Gómez-Avilés, A.; Appl. Catal., A 2014, 474, 211.

7. Liu, C. H.; Lin, C. Y.; Chen, J. L.; Lu, K. T.; Lee, J. F.; Chen, J. M.; J. Catal. 2017, 350, 21.

8. Ahmad, J. U.; Räisänen, M. T.; Leskelä, M.; Repo, T.; Appl. Catal., A 2009, 371, 17.

9. Sudarsanam, P.; Mallesham, B.; Naga Durgasri, D.; Reddy, B. M.; J. Ind. Eng. Chem. 2014, 20, 3115.

10. Yu, X.; Huo, Y.; Yang, J.; Chang, S.; Ma, Y.; Huang, W.; Appl. Surf. Sci. 2013, 280, 450.

11. Kim, H. J.; Jeon, Y. K.; Park, J.; Shul, Y. G.; J. Mol. Catal. A: Chem. 2013, 378, 232.

12. Farsani, M. R.; Jalilian, F.; Yadollahi, B.; Rudbari, H. A.; Polyhedron 2014, 76, 102.

13. Tokarz-Sobieraj, R.; Grybos, R.; Filek, U.; Micek-Ilnicka, A.; Niemiec, P.; Kirpsza, A.; Witko, M.; Catal. Today 2015, 257, 72.

14. Leng, Y.; Zhao, P.; Zhang, M.; Wang, J.; J. Mol. Catal. A: Chem. 2012, 358, 67.

15. Pamin, K.; Prończuk, M.; Basąg, S.; Kubiak, W.; Sojka, Z.; Połtowicz, J.; Inorg. Chem. Commun. 2015, 59, 13.

16. Zhao, W.; Zhang, Y.; Ma, B.; Ding, Y.; Qiu, W.; Catal. Commun. 2010, 11, 527.

17. Farsani, M. R.; Yadollahi, B.; J. Mol. Catal. A: Chem. 2014, $392,8$.

18. Choi, J. H.; Kang, T. H.; Song, J. H.; Bang, Y.; Song, I. K.; Catal. Commun. 2014, 43, 155.

19. Dong, D. R.; Choi, J. H.; Park, S.; Song, I. K.; Appl. Catal., A 2011, 394, 201.

20. Wang, S. S.; Zhang, J.; Zhou, C. L.; Vo-Thanh, G.; Liu, Y.; Catal. Commun. 2012, 28, 152. 
21. Pathan, S.; Patel, A.; Appl. Catal., A 2013, 459, 59.

22. Madhusudhan Rao, P.; Wolfson, A.; Kababya, S.; Vega, S.; Landau, M. V.; J. Catal. 2005, 232, 210.

23. Chen, L. J.; Feng, T.; Wang, P. F.; Chen, Z. W.; Yana, R. Q.; Liao, B.; Xiang, Y. J.; Appl. Catal., A 2016, 523, 304.

24. Ghanbari-Siahkali, A.; Philippou, A.; Dwyer, J.; Anderson, M. W.; Appl. Catal., A 2000, 192, 57.

25. Izumi, Y.; Urabe, K.; Chem. Lett. 1981, 10, 663.

26. Hu, C.; He, Q.; Zhang, Y.; Liu, Y.; Zhang, Y.; Tang, T.; Zhang, J.; Wang, E.; Chem. Commun. 1996, 2, 121.

27. Vlaic, G.; Di Monte, R.; Fornasiero, P.; Fonda, E.; Kaspar, J.; Graziani, M.; J. Catal. 1999, 182, 378.

28. Gokhan, E.; Demet, O.; Birgul, Z. K.; Catal. Commun. 2017, $89,56$.

29. Reddy, B. M.; Khan, A.; Catal. Surv. Asia 2005, 9, 155.

30. Narasimharao, K.; Ali, T. T.; Catal. Lett. 2013, 143, 1074.

31. Zhang, H.; Xie, Y.; Sun, Z.; Tao, R.; Huang, C.; Zhao, Y.; Liu, Z.; Langmuir 2011, 27, 1152.

32. Abad, A.; Concepcion, P.; Corma, A.; Garcfa, H.; Angew. Chem., Int. Ed. 2005, 44, 4066.

33. Ragupathi, C.; Judith Vijaya, J.; Narayanan, S.; Jesudoss, S. K.; John Kennedy, L.; Ceram. Int. 2015, 41, 2069.
34. Zheng, A.; Huang, S. J.; Liu, S. B.; Deng, F.; Phys. Chem. Chem. Phys. 2011, 13, 14889.

35. Zheng, A.; Li, S.; Liu, S. B.; Deng, F.; Acc. Chem. Res. 2016, $49,655$.

36. Zheng, A.; Huang, S. J.; Chen, W. H.; Wu, P. H.; Zhang, H.; Lee, H. K.; De Ménorval, L. C.; Deng, F.; Liu, S. B.; J. Phys. Chem. A 2008, 112, 7349.

37. Zheng, A.; Zhang, H.; Lu, X.; Liu, S. B.; Deng, F.; J. Phys. Chem. B 2008, 112, 4496.

38. Essayem, N.; Gayraud, A. P. Y.; Vedrine, J. C.; Taarit, Y. B.; J. Catal. 2001, 197, 273.

39. Huang, S. J.; Yang, C. Y.; Zheng, A.; Feng, N.; Yu, N.; Wu, P. H.; Chang, Y. C.; Lin, Y. C.; Deng, F.; Liu, S. B.; Chem. Asian J. 2011, 6, 137.

40. Khder, A. E. R. S.; Hassan, H. M. A.; El-Shal, M. S.; Appl. Catal., A 2012, 411-412, 77.

41. Ramachandra, H.; Rangappa, K. S.; Mahadevappa, D. S.; MadeGowda, N. M.; Monatsh. Chem. 1996, 127, 241.

42. Setareh, S.; Nooredin, G.; Monatsh. Chem. 2016, 147, 1531.

Submitted: January 25, 2017 Published online: June 26, 2017 